\title{
AK098656: a new biomarker of coronary stenosis severity in hypertensive and coronary heart disease patients
}

\author{
Xin Wang ${ }^{1,2+}$, Ya-li Wu ${ }^{1,2+}$, Yuan-yuan Zhang ${ }^{1,2}$, Jing Ke ${ }^{1,2}$, Zong-wei Wang ${ }^{1,2}$, Bao-yu Zhang ${ }^{1,2}$, Yan Ma Ma,
} Long-yan Yang ${ }^{1,2^{*}}$ and Dong Zhao ${ }^{1,2^{*}}$

\begin{abstract}
Background: AK098656 may be an adverse factor for coronary heart disease (CHD), especially in patients with hypertension. This study aimed to analyze the effect of AK098656 on CHD and CHD with various complications.

Methods: A total of 117 CHD patients and 27 healthy control subjects were enrolled in the study. Plasma AK098656 expression was determined using the quantitative real-time polymerase chain reaction. Student's $t$-test was used to compare AK098656 expression levels in different groups. Receiver operating characteristic (ROC) curve and area under the curve (AUC) were used to quantify the discrimination ability between CHD patients and health controls and between CHD and CHD + complications patients. The relationship between AK098656 and coronary stenosis was analyzed using Spearman's correlation.

Results: AK098656 expression was remarkably higher in CHD patients than in healthy controls $(P=0.03)$. The ROC curve revealed an effective predictive AK098656 expression value for CHD risk, with an AUC of 0.656 (95\% Cl 0.501-0.809). Moreover, AK098656 expression was increased in CHD + complications patients compared to CHD patients alone $(P=0.005)$, especially in patients with hypertension ( $C H D+h H T N, P=0.030)$. The ROC curve revealed a predictive AK098656 prognostic value for discriminating between CHD and CHD + hHTN patients, with an AUC of 0.666 (95\% Cl 0.528-0.805). There was no significant difference in AK098656 expression in CHD patients with diabetes mellitus compared to CHD patients alone. In addition, AK098656 expression in CHD patients was positively correlated with stenosis severity $(R=0.261, P=0.006)$.
\end{abstract}

Conclusion: AK098656 expression was significantly increased in patients with CHD, especially those with hypertension, and its expression level was positively correlated with the degree of coronary stenosis. This implied that AK098656 may be a risk factor for CHD and can potentially be applied in clinical diagnosis or provide a novel target for treatment.

Keywords: AK098656, Coronary heart disease, Hypertension, Complications, Stenosis

\footnotetext{
*Correspondence: lingbeiyangstudent@163.com; zhaodong@ccmu.edu.cn

${ }^{\dagger}$ Xin Wang and Ya-li Wu contributed equally to this work

${ }^{1}$ Center for Endocrine Metabolism and Immune Diseases, Beijing Luhe Hospital, Capital Medical University, Beijing, China

Full list of author information is available at the end of the article
}

\begin{abstract}
Introduction
Cardiovascular disease is the leading cause of death worldwide. Coronary heart disease (CHD) is the most harmful disease and leading cause of hospitalization and death among adult heart disease patients [1-3]. Multiple studies have shown that controlling the risk factors can significantly reduce CHD morbidity and mortality [4-8].
\end{abstract} permits use, sharing, adaptation, distribution and reproduction in any medium or format, as long as you give appropriate credit to the original author(s) and the source, provide a link to the Creative Commons licence, and indicate if changes were made. The images or other third party material in this article are included in the article's Creative Commons licence, unless indicated otherwise in a credit line to the material. If material is not included in the article's Creative Commons licence and your intended use is not permitted by statutory regulation or exceeds the permitted use, you will need to obtain permission directly from the copyright holder. To view a copy of this licence, visit http://creativecommons.org/licenses/by/4.0/. The Creative Commons Public Domain Dedication waiver (http://creativeco mmons.org/publicdomain/zero/1.0/) applies to the data made available in this article, unless otherwise stated in a credit line to the data. 
Many traditional risk factors, such as family history of CHD, hypertension, diabetes, obesity, and smoking, already have been targeted for early interventions in clinical work $[9,10]$. However, current research has shown that some nontraditional factors, such as autoimmune diseases, high sensitivity C-reactive protein, and homocysteine, also play important roles in the occurrence and development of $\mathrm{CHD}$ and need to be given sufficient attention.

Long non-coding (lnc) RNA has a length of more than 200 nucleotides and limited protein-coding ability and can be considered as "transcriptional junk" [11]. However, growing evidence has suggested that lncRNA has important regulatory functions and is associated with the development of complex diseases, such as cardiovascular diseases and cancer [12-15]. Accumulating studies have revealed that multiple lncRNAs are implicated in CHD. An earlier study has shown that lncRNA-p21 enhances p53 activity via the p53 signaling pathway, thereby inhibiting the formation of atherosclerosis [16]. CoroMarker is very stable in the plasma of CHD patients and may become a new plasma biomarker for CHD diagnosis [17]. $\mathrm{H} 19$ is re-expressed in atherosclerotic patients, and its polymorphism is related to the risk of CHD [18].

A new human vascular smooth muscle cells (VSMCs)dominant lncRNA AK098656 can accelerate the degradation of contractile proteins, increase the synthesis phenotype in VSMCs, and eventually lead to narrowing of resistant arteries and hypertension [19]. VSMCs phenotype conversion has crucial pathophysiological significance in different stages of atherosclerosis, while lncRNAs are important factors that regulate VSMCs function and phenotype, as well as occurrence and development of related diseases. However, because AK098656 is a newly discovered lncRNA specifically expressed in VSMCs, its relationship with CHD has not been reported. In this study, we will sought to elucidate that AK098656 is a new molecule that regulates the development of coronary heart disease.

\section{Materials and methods \\ Patients and samples}

Due to the limited data on AK098656 expression in CHD patients, plasma and clinical data for healthy controls $(\mathrm{n}=27)$ and CHD patients (CHD: $\mathrm{n}=25, \mathrm{CHD}+\mathrm{hDM}$ : $\mathrm{n}=24, \mathrm{CHD}+\mathrm{hHTN}: \mathrm{n}=41$, and CHD +hDM +hHTN: $\mathrm{n}=27$ ) were collected in Beijing Luhe Hospital, Capital Medical University (Beijing, China) between September 2019 and January 2020. All participants were Han individuals from the same region. Patient inclusion criteria were as follows: (1) patients diagnosed with CHD. CHD was defined by coronary artery stenosis of $\geq 50 \%$ as determined by coronary angiography. Hypertension was defined by systolic blood pressure of at least $140 \mathrm{~mm} \mathrm{Hg}$ or diastolic blood pressure of at least $90 \mathrm{~mm} \mathrm{Hg}$. Diabetes was defined by fasting blood glucose level of at least $7.0 \mathrm{mmol} / \mathrm{L}$ or blood glucose level of $11.0 \mathrm{mmol} / \mathrm{L}$ or more $2 \mathrm{~h}$ after an oral glucose load of $75 \mathrm{~g}$; and (2) age of 35-80 years. Exclusion criteria included other clinically detectable cardiovascular diseases. The study complied with the Helsinki Declaration for investigation of human subjects and obtained ethical approval from the competent Institutional Review Boards of Beijing Luhe Hospital, Capital Medical University. All participants provided written informed consent.

\section{RNA isolation and qPCR}

Blood samples of patients were collected within $24 \mathrm{~h}$ after admission to the Cardiology Intensive Care Unit. After centrifugation at $5000 \mathrm{~g}$ for $10 \mathrm{~min}$, the plasma was separated from the whole blood and divided into two portions. All samples were stored at $-80{ }^{\circ} \mathrm{C}$. Total RNA from human plasma was isolated using the TRIzol LS (Invitrogen, USA) and converted to cDNA using a cDNA synthesis kit (BioRad, USA) according to manufacturer instructions. The expression levels of lncRNAAK098656 were determined using SYBR (BioRad, USA) and normalized using $18 \mathrm{~s}$ cDNA. The primer sequences were as follows: AK098656, forward: 5'-CCTCATTTG CTGGCACCTG-3', reverse: 5'-GGGAGGCAAGGTAGA AGGGA-3'; 18S, forward, 5'-GTAACCCGTTGAACC CCATT-3', and reverse: 5'-CCATCCAATCGGTAGTAG CG-3'.

\section{Biochemical measurements}

Blood samples were collected for triglyceride, cholesterol, and high- and low-density lipoprotein cholesterol analysis using a Hitachi 7600-020 clinical analyzer (Hitachi, Tokyo, Japan). C-peptide and insulin are determined by Cobas e601 (Roche Diagnostics, Mannheim, Germany).

\section{Coronary angiography}

Coronary angiography methods have been previously described [20]. Patients with coronary artery stenosis $\geq 50 \%$ were diagnosed with CHD. CHD severity was further divided into three groups: mild, moderate, and severe. Mild refers to the degree of stenosis $<70 \%$ for all coronary arteries, moderate refers to the degree of stenosis $\geq 70 \%$ for one coronary artery, and severe refers to the degree of stenosis $\geq 70 \%$ for two or more coronary arteries.

\section{Statistical analysis}

To explore the relationship between AK098656 and CHD, Student's $t$-test between healthy controls and CHD 
groups was used. Furthermore, receiver operating characteristic (ROC) curve was utilized to estimate the discrimination ability of AK098656 in CHD and to quantify the discrimination ability using an area under the curve (AUC), which is widely used in pattern recognition. The distribution of AUC values was between 0 and 1 . AUC $>0.5$ meant that the indicator had the ability to distinguish between conditions in question. The larger the AUC value, the stronger the ability to distinguish.

Student's $t$-test was then used between the CHD and $\mathrm{CHD}+$ complications groups $(\mathrm{CHD}+\mathrm{hDM}, \mathrm{CHD}+\mathrm{hHTN}$, and $\mathrm{CHD}+\mathrm{hDM}+\mathrm{hHTN}, \mathrm{n}=92)$ to explore the relationship between AK098656 and complications with CHD. The ROC curve and AUC were used to quantify the discrimination ability between $\mathrm{CHD}$ and $\mathrm{CHD}+$ complications. In addition, Student's $t$-test was utilized between the CHD and CHD + hDM groups and with the CHD + hHTN group separately to explore which complication would result in a greater effect on AK098656. The ROC curve and AUC were also used to quantify the differences.

Hypertension is one of the most potent risk factors for CHD development, which increases the risk of stenosis in CHD patients. The correlation between AK098656 and CHD stenosis was evaluated using Spearman's correlation analysis.

\section{Results}

General characterization of study subjects

Table 1 provides the general characteristics for participants with or without CHD and CHD accompanied by complications. The study included 27 non-CHD participants with an average age of 49 years (13 men). For CHD patients (19 men), the average age was 64 years. Compared to healthy controls, CHD and $\mathrm{CHD}+$ complications patients had a higher heart rate and increased systolic blood pressure. CHD patients diagnosed with diabetes had a higher fasting glucose level.

\section{AK098656 expression correlation for CHD risk}

AK098656 expression level was significantly higher in CHD patients compared to healthy controls $(\mathrm{P}=0.038$; Fig. 1A). In order to quantify the discrimination ability between healthy controls and CHD patients, ROC curve analysis revealed that AK098656 was a valuable predictor for $\mathrm{CHD}$ risk $(\mathrm{AUC}=0.656,95 \%$ CI $0.501-$ 0.809; Fig. 1B).

Table 1 Demographics and clinical characteristics

\begin{tabular}{|c|c|c|c|c|c|}
\hline Characters & $\begin{array}{l}\text { Healthy controls } \\
(n=27)\end{array}$ & $\begin{array}{l}\text { CHD } \\
(n=25)\end{array}$ & $\begin{array}{l}\text { CHD+hDM } \\
(n=24)\end{array}$ & $\begin{array}{l}\text { CHD + hHTN } \\
(n=41)\end{array}$ & $\begin{array}{l}\text { CHD }+h D M+h H T N \\
(n=27)\end{array}$ \\
\hline Age, years & $48.9 \pm 14.9$ & $62.2 \pm 13.8$ & $63.0 \pm 10.4$ & $62.4 \pm 11.4$ & $68.3 \pm 11.3$ \\
\hline Gender, M/F & $13 / 14$ & $19 / 6$ & $13 / 11$ & $29 / 12$ & $15 / 12$ \\
\hline Heart rate, beats/min & $60.7 \pm 41.9$ & $73.8 \pm 15.6$ & $81.9 \pm 17.2$ & $73.8 \pm 17.4$ & $81.9 \pm 21.0$ \\
\hline Hypertension history & No & No & No & Yes & Yes \\
\hline \multicolumn{6}{|l|}{ Drug use } \\
\hline Aspirin, n (\%) & $3(11.1 \%)$ & $22(88 \%)$ & $24(100 \%)$ & $33(80.5 \%)$ & $21(77.8 \%)$ \\
\hline Clopidogrel, (\%) & 0 & $9(36 \%)$ & $15(62.5 \%)$ & $18(43.9 \%)$ & $15(55.6 \%)$ \\
\hline Statin, n (\%) & 0 & $17(68 \%)$ & $23(95.8 \%)$ & $35(85.4 \%)$ & $20(74.1 \%)$ \\
\hline Calcium antagonist, (\%) & $4(14.8 \%)$ & $2(8 \%)$ & $2(8.3 \%)$ & $17(41.5 \%)$ & $13(48.1 \%)$ \\
\hline ß-blocker, n (\%) & $3(11.1 \%)$ & $13(52 \%)$ & $16(66.7 \%)$ & $24(58.5)$ & $12(44.4 \%)$ \\
\hline Total cholesterol, mmol/L (SCHO) & $4.48 \pm 0.88$ & $4.78 \pm 1.21$ & $4.64 \pm 1.09$ & $4.21 \pm 1.12$ & $3.93 \pm 0.89$ \\
\hline Total trigly (STG) & $1.19 \pm 0.71$ & $1.62 \pm 0.87$ & $1.94 \pm 1.28$ & $1.50 \pm 0.80$ & $1.65 \pm 0.97$ \\
\hline HDL cholesterol, mmol/L (SHDL) & $1.37 \pm 0.39$ & $1.14 \pm 0.25$ & $1.06 \pm 0.24$ & $1.09 \pm 0.23$ & $1.12 \pm 0.24$ \\
\hline LDL cholesterol, mmol/L (SLDL) & $2.67 \pm 0.67$ & $3.09 \pm 0.84$ & $3.15 \pm 0.83$ & $2.73 \pm 0.90$ & $2.42 \pm 0.74$ \\
\hline Fasting glucose, mmol/L (SFBG) & $5.49 \pm 1.20$ & $5.55 \pm 0.99$ & $8.54 \pm 3.37$ & $5.77 \pm 1.37$ & $8.98 \pm 2.99$ \\
\hline Insulin & $10.96 \pm 6.69$ & $14.75 \pm 14.41$ & $18.09 \pm 20.80$ & $17.83 \pm 16.40$ & $24.00 \pm 27.50$ \\
\hline C-peptide & $2.35 \pm 0.69$ & $3.76 \pm 12.71$ & $3.78 \pm 4.01$ & $3.87 \pm 2.08$ & $4.25 \pm 3.07$ \\
\hline \multicolumn{6}{|l|}{ Coronary stenosis } \\
\hline Mild & - & 4 & 2 & 4 & 3 \\
\hline Moderate & - & 7 & 4 & 14 & 5 \\
\hline Severe & - & 8 & 8 & 12 & 8 \\
\hline Not available & - & 6 & 10 & 11 & 11 \\
\hline
\end{tabular}




\section{a}

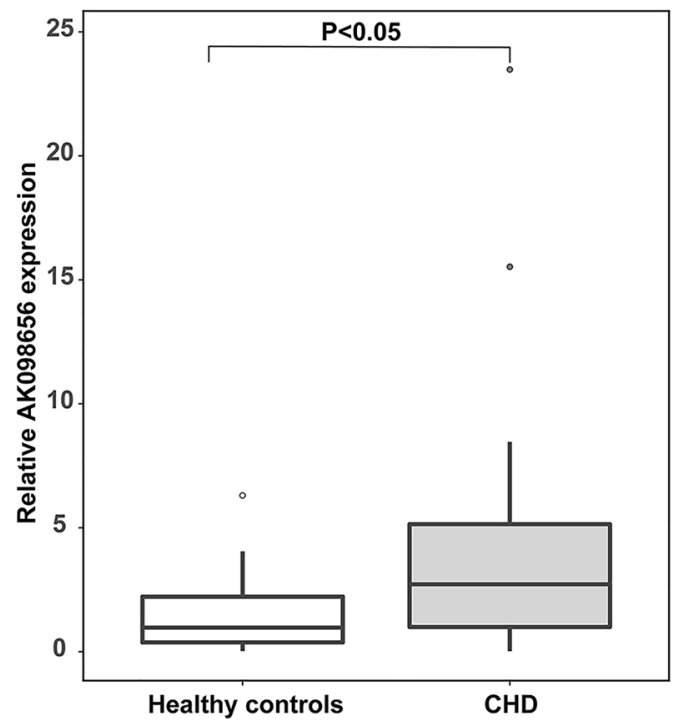

b

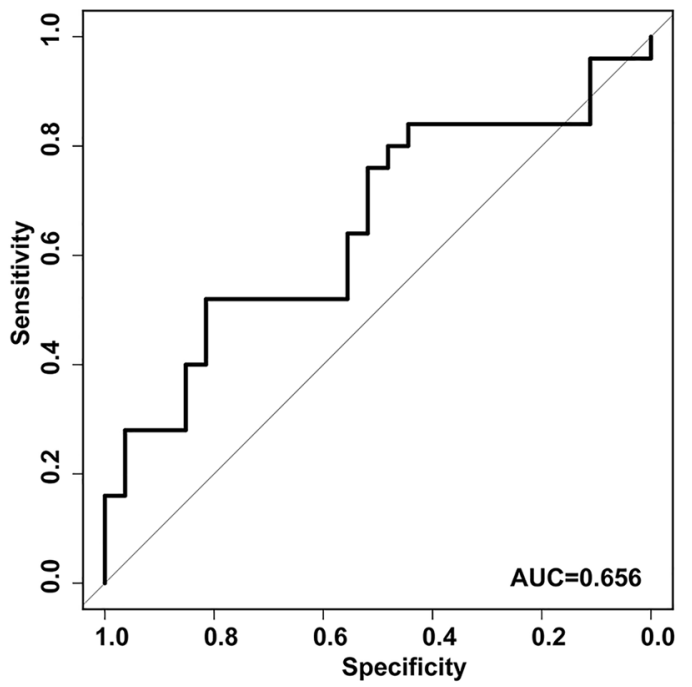

Fig. 1 Diagnostic value of AK098656 for CHD. a AK098656 expression level in healthy controls and CHD groups. b Discrimination ROC for healthy controls and CHD groups

\section{Independent predictive value for AK098656 expression for CHD complication risk}

Because CHD is often accompanied by other chronic complications, such as hypertension and diabetes, AK098656 expression level in CHD and CHD + complications patients was further analyzed. The AK098656 expression level in $\mathrm{CHD}+$ complications patients was significantly higher than that in $\mathrm{CHD}$ alone patients $(\mathrm{P}=0.005$; Fig. $2 \mathrm{~A})$. The ROC curve analysis revealed that AK098656 had the ability to distinguish between the CHD and CHD+complications groups (AUC $=0.673$, 95\% CI 0.552-0.793; Fig. 2B). To further analyze the effect of AK098656 on CHD complications, we examined the expression of AK098656 in different groups of CHD complications. The expression of AK098656 in CHD + hHTN patients was significantly higher than that in CHD alone patients $(\mathrm{P}=0.030)$. In $\mathrm{CHD}$ patients with diabetes mellitus, AK098656 expression was slightly higher than that in CHD patients, although no statistical difference was present $(P=0.365)$. In addition, there was no significant difference in AK098656 expression level between $\mathrm{CHD}+\mathrm{hDM}$ and $\mathrm{CHD}+\mathrm{hHTN}$ patients $(\mathrm{P}=0.135$; Fig. 2C). The ROC analysis implied that AK098656 had the potential to distinguish between $\mathrm{CHD}$ and
CHD + hHTN groups $(\mathrm{AUC}=0.666,95 \%$ CI $0.528-$ 0.805; Fig. 2D).

\section{AK098656 increases coronary stenosis risk in CHD patients} CHD severity was divided into three degrees: mild (stenosis degree for all coronary arteries was $<70 \%$ ), moderate (stenosis degree of one coronary artery was $\geq 70 \%$ ), and severe (the stenosis degree of two or more coronary arteries was $\geq 70 \%$; Fig. $3 \mathrm{~A}-\mathrm{C}$ ). It is worth noting that AK098656 expression was gradually upregulated with the increase in stenosis degree (Fig. 3D) and was positively associated with stenosis severity $(R=0.261, P=0.006)$. It is possible that a higher AK098656 expression may indicate a more severe coronary stenosis.

\section{Discussion}

In this study, human-specific lncRNA AK098656 was significantly increased in CHD patients, especially in those with hypertension. In addition, AK098656 was positively correlated with coronary stenosis severity in CHD patients. This study not only suggested that AK098656 could predict CHD severity, but also proposed that elevated AK098656 in hypertensive individuals may 


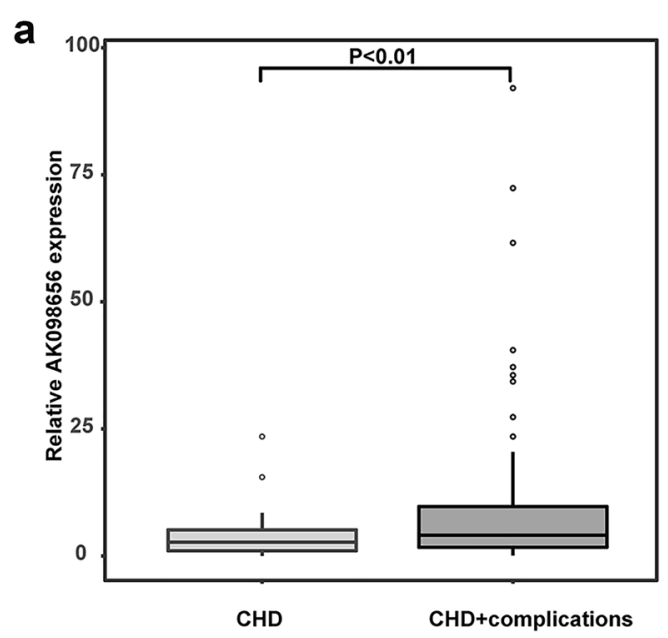

C

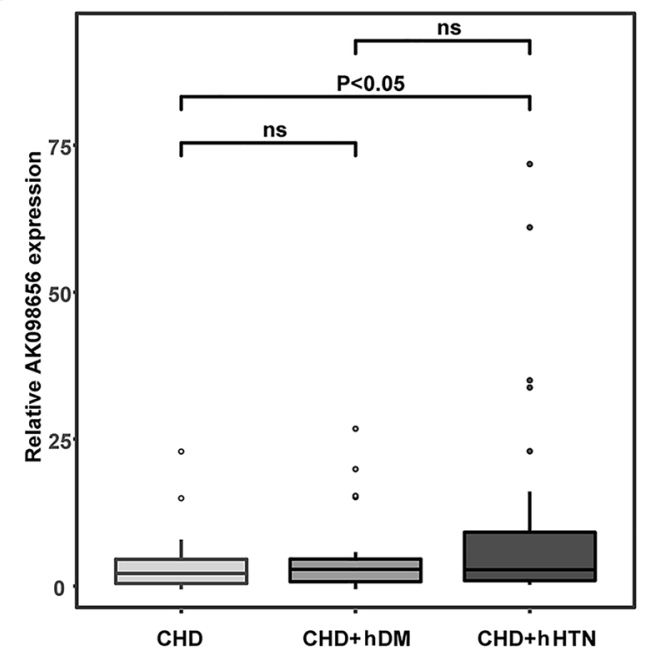

b

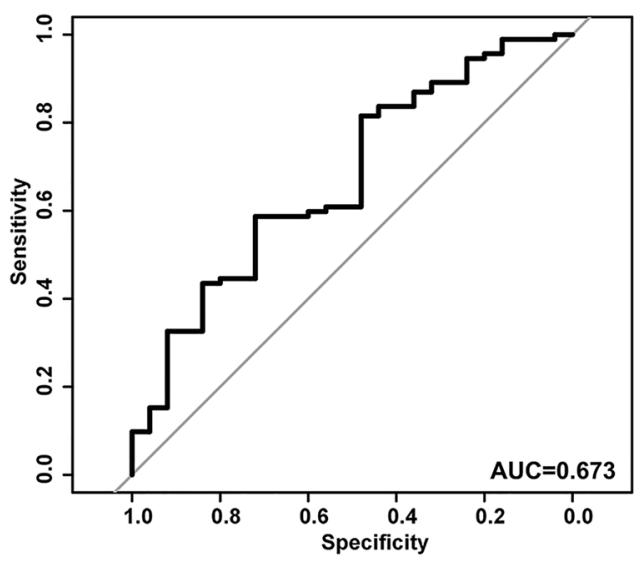

d

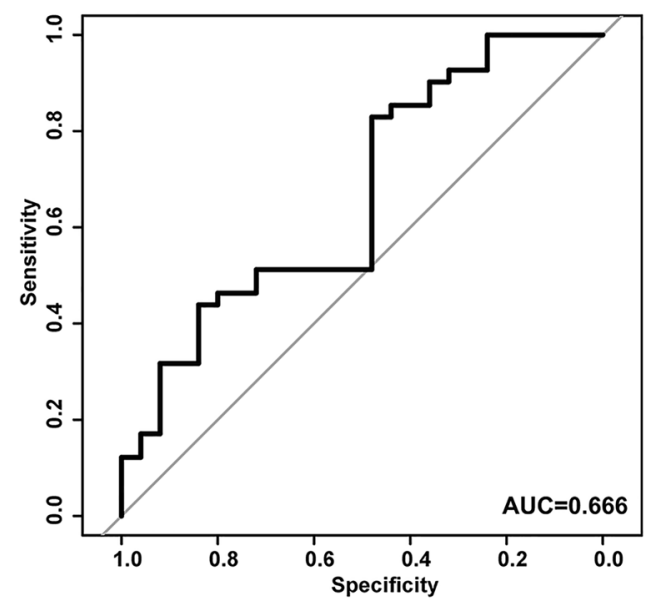

Fig. 2 Predictive AK098656 value for CHD patients with complications. a AK098656 expression level boxplot for the CHD and CHD + complications groups. b Discrimination ROC for the CHD and CHD + complications groups. c An AK098656 expression boxplot for the CHD, CHD + hDM, and CHD + hHTN groups. d Discrimination ROC for the CHD and CHD + hHTN groups

enhance the risk of CHD. The results also confirmed a previous report that AK098656 was upregulated in hypertensive patients compared to normotensive controls [19]. A great deal of research shows that diabetes has a significant effect on coronary arteries and cardiac microcirculation, but also stipulated the idea that elevated. Both insulin resistance and hyperglycemia inflict significant damage to the cardiovascular system [21, 22]. Thus, AK098656 expression was further investigated in CHD + hDM patients. However, AK098656 expression in the CHD + hDM group was not greater than that in the CHD group. An explanation for this observation cannot be suggested based on the current experiment data. However, the insignificant difference between the
$\mathrm{CHD}+\mathrm{hDM}$ and CHD groups may be due to the study's small sample size.

Differentiation and phenotypic transformation of VSMCs are key initial steps in cardiovascular diseases, such as hypertension, atherosclerosis, and restenosis after angioplasty [23]. Many studies have confirmed that under the influence of different external factors, VSMCs show different phenotypic characteristics. Thus, transformation of different VSMC phenotypes plays an important role in the occurrence and development of a variety of vascular diseases [24]. Therefore, it is initial key steps to investigate the molecular mechanisms of VSMC differentiation and phenotypic transformation for prevention and treatment of these diseases. Differentiated and mature VSMCs mainly 

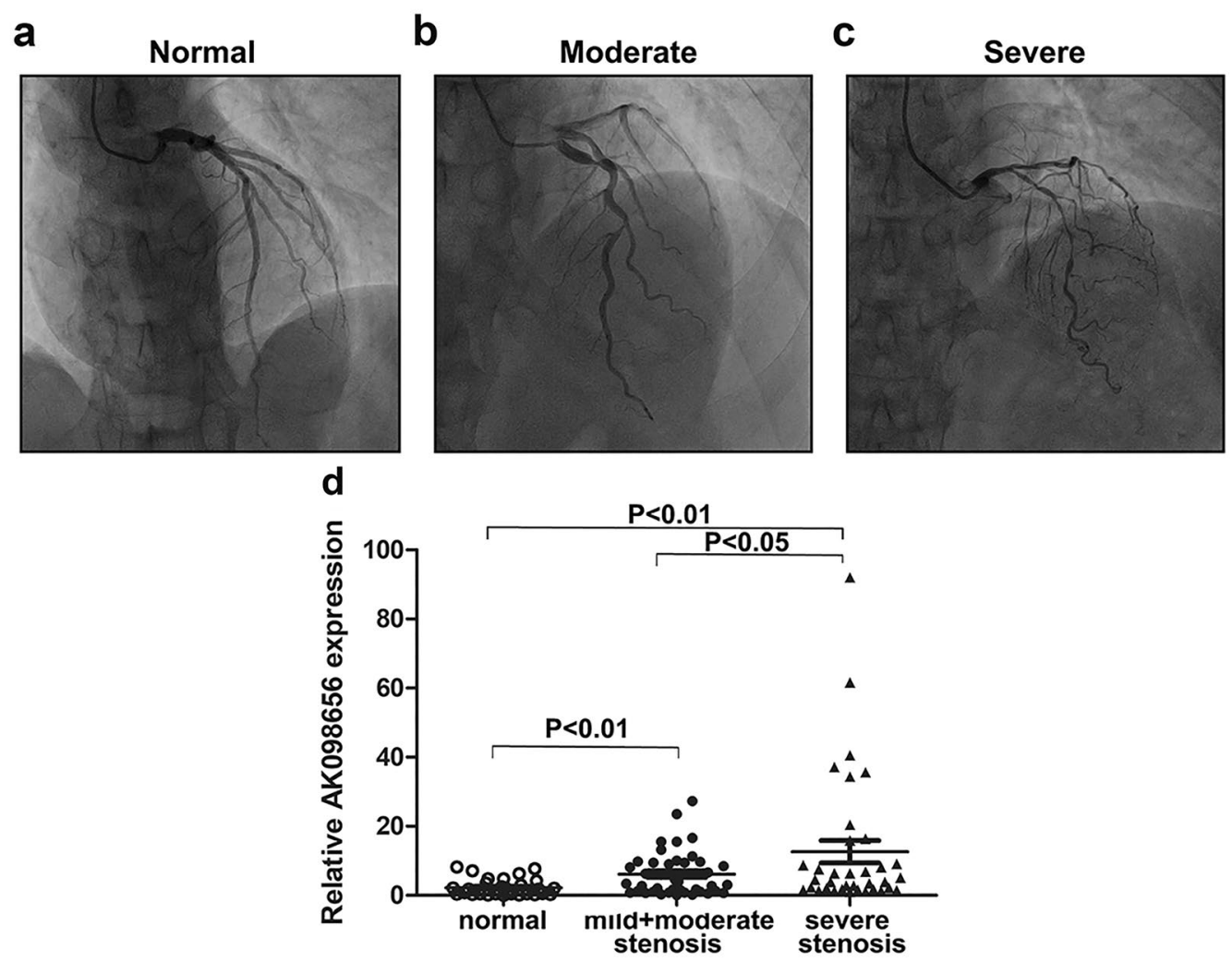

Fig. 3 Correlation between AK098656 expression and coronary stenosis. Coronary angiography for a normal, b mild coronary stenosis, $\mathbf{c}$ and severe coronary stenosis. $\mathbf{d}$ The AK098656 expression level in different stenosis degrees (normal, $n=27$; mild + moderate, $n=43$; and severe, $n=36$ )

maintain their vascular morphology, while dedifferentiated "secretory" VSMCs secrete a large amount of extracellular matrix (ECM) through migration and proliferation. They also play an important role in the occurrence and development of a variety of vascular diseases, including CHD [24, 25]. Angiotensin II and epidermal growth factor are widely recognized to induce proliferation and migration of mature VSMCs $[26,27]$. Insulin-like growth factor-1 (IGF-1) is one of the most intensively studied factors that can inhibit phenotypic VSMC transformation. IGF-1 activates the downstream PI3K-AKT signaling pathway by binding to the IGF receptor, thereby increasing the expression of VSMC systolic protein [28]. In addition, tumor growth factor, rapamycin, and microRNA (miR-221, $-222,-21,-146 \mathrm{~A}$, and -133$)$ are all involved in the regulation of cell proliferation, apoptosis and migration [29, 30]. According to Jin et al. study, transgenic AK098656 rats spontaneously developed hypertensive phenotypes accompanied by reduced lumen diameter and enhanced media/lumen ratio [19]. Then, AK098656 directly bound to MYH11, which was a smooth muscle cell-specific contractile protein. Fibronectin is another
AK098656 binding protein that is an essential ECM component [19]. Both MYH11 and fibronectin promote VSMCs plasticity and synthetic phenotype in hypertension pathogenesis [31, 32]. To some extent, the above evidence may explain the mechanism of increased AK098656 expression aggravating coronary artery stenosis, which eventually affects the stenosis score in CHD patients.

Increasing evidence has demonstrated that lncRNAs are not "transcriptional junk". In fact, lncRNAs play various regulatory roles in each step of gene expression and translation via epigenetic regulation, alternative splicing regulation, or acting as a molecular sponge [33]. A large number of lncRNAs may be part of a complex regulatory network in physiopathology in the cardiovascular system. Consequently, lncRNAs may open up new avenues for diagnosis or serve as therapeutic targets for CHD treatment. For instance, long intergenic noncoding RNA-p21 (lincRNA-p21) has been reported to be down-regulated in patients with CHD, and injection of lentivirus si-lincRNA-p21 at the injured site induced neointimal hyperplasia [16]. LncRNA-MALAT1 mediates endothelial progenitor cells autophagy by activating mTOR signaling 
pathway and improves coronary atherosclerotic heart disease [34].

There were some limitations in this study. (1) A total of 144 subjects were analyzed in this study, resulting in a relatively small sample size, which may have resulted in insufficient statistical power. (2) Because the clinical data and samples were all collected from a general population at a single center, selection bias may be present due to regional restrictions. Therefore, the results should be further confirmed via large, multi-center, prospective clinical trials. (3) Detailed lncRNA-AK098656 mechanisms in $\mathrm{CHD}$ or $\mathrm{CHD}+$ complications patients were not investigated.

\section{Conclusions}

In conclusion, our present study found that AK098656 expression in CHD patients was significantly higher than that in healthy controls. The results showed that AK098656 expression in CHD+hHTN and $\mathrm{CHD}+\mathrm{hDM}+\mathrm{hHTN}$ patients was significantly increased compared to CHD alone patients. AK098656 expression was also positively correlated with the degree of coronary artery stenosis. Thus, this study revealed a novel molecule that regulates CHD development.

\begin{abstract}
Abbreviations
AUC: Area under the curve; CHD: Coronary heart disease; ECM: Extracellular matrix; hDM: Human diabetes mellitus; hHTN: Human hypertension; IGF-1: Insulin-like growth factor-1; IncRNA: Long non-coding (Inc) RNA; VSMCs: Vascular smooth muscle cells.
\end{abstract}

\section{Acknowledgements}

We thank International Science Editing (http://www.internationalscienceediti ng.com) for editing this manuscript.

\section{Authors' contributions}

$X W, Y W$, and DZ designed the experiments. YW, YZ, BYZ, and $Y M$ were responsible for sample collection and database management. XW performed all RNA isolations and gPCR testing, as well as data analysis. ZWW undertook the detection work of C-peptide and insulin. XW and YLW wrote the manuscript. $D Z, L Y$, and JK supervised the experiments and revised the manuscript. All authors read and approved the final manuscript.

\section{Funding}

This study was supported by the National Natural Science Foundation of China $(81800768,81800723)$.

\section{Availability of data and materials}

All data generated or analyzed during this study are included in this published article.

\section{Declarations}

\section{Ethics approval and consent to participate}

The study complied with the Helsinki Declaration for investigation of human subjects and obtained ethical approval from the competent Institutional Review Boards of Beijing Luhe Hospital, Capital Medical University. All participants provided written informed consent.
In addition, all participants provided informed consent when they were enrolled in the study.

\section{Consent for publication}

Not applicable.

\section{Competing interests}

The authors declare that the research was conducted in the absence of any commercial or financial relationships that could be construed as a potential conflict of interest.

\section{Author details}

${ }^{1}$ Center for Endocrine Metabolism and Immune Diseases, Beijing Luhe Hospital, Capital Medical University, Beijing, China. ${ }^{2}$ Beijing Key Laboratory of Diabetes Research and Care, Beijing, China.

Received: 28 September 2021 Accepted: 4 January 2022

Published online: 15 January 2022

References

1. Benziger CP, Roth GA, Moran AE. The global burden of disease study and the preventable burden of NCD. Glob Heart. 2016;11:393-7. https://doi. org/10.1016/j.gheart.2016.10.024.

2. De Hert M, Detraux J, Vancampfort D. The intriguing relationship between coronary heart disease and mental disorders. Dialogues Clin Neurosci. 2018;20:31-40.

3. Mohsen N, Amanuel AA, Cristiana A, Kaja MA, Foad AA, Semaw FA, et al. Global, regional, and national age-sex specific mortality for 264 causes of death, 1980-2016: a systematic analysis for the Global Burden of Disease Study 2016. Lancet. 2017;390:1151-210. https://doi.org/10.1016/s01406736(17)32152-9.

4. Wadhera RK, Steen DL, Khan I, Giugliano RP, Foody JM. A review of low-density lipoprotein cholesterol, treatment strategies, and its impact on cardiovascular disease morbidity and mortality. J Clin Lipidol. 2016;10:472-89. https://doi.org/10.1016/j.jacl.2015.11.010.

5. Atkins JL, Whincup PH, Morris RW, Lennon LT, Papacosta O, Wannamethee SG. Dietary patterns and the risk of CVD and all-cause mortality in older British men. Br J Nutr. 2016;116:1246-55. https://doi.org/10. 1017/S0007114516003147.

6. Brunstrom M, Carlberg B. Association of blood pressure lowering with mortality and cardiovascular disease across blood pressure levels: a systematic review and meta-analysis. JAMA Intern Med. 2018;178:28-36. https://doi.org/10.1001/jamainternmed.2017.6015.

7. Mons U, Muezzinler A, Gellert C, Schottker B, Abnet CC, Bobak M, et al. Impact of smoking and smoking cessation on cardiovascular events and mortality among older adults: meta-analysis of individual participant data from prospective cohort studies of the CHANCES consortium. BMJ. 2015;350: h1551. https://doi.org/10.1136/bmj.h1551.

8. Goldberg RB, Aroda VR, Bluemke DA, Barrett-Connor E, Budoff M, Crandall $J P$, et al. Effect of long-term metformin and lifestyle in the diabetes prevention program and its outcome study on coronary artery calcium. Circulation. 2017;136:52-64. https://doi.org/10.1161/CIRCULATIONAHA. 116.025483.

9. Kilic S, Saracoglu E, Cekici Y, Yildirim A, Kuzu Z, Kilic DD, et al. Comparison of secondary prevention in coronary heart disease patients living in rural and urban areas. Turk Kardiyol Dern Ars. 2019;47:128-36. https://doi.org/ 10.5543/tkda.2018.68782.

10. Yusuf S, Islam S, Chow CK, Rangarajan S, Dagenais G, Diaz R, et al. Use of secondary prevention drugs for cardiovascular disease in the community in high-income, middle-income, and low-income countries (the PURE Study): a prospective epidemiological survey. Lancet. 2011;378:1231-43. https://doi.org/10.1016/s0140-6736(11)61215-4.

11. Miranda-Castro R, de-Los-Santos-Alvarez N, LoboCastanon MJ. Long noncoding RNAs: from genomic junk to rising stars in the early detection of cancer. Anal Bioanal Chem. 2019;411:4265-75. https://doi.org/10.1007/ s00216-019-01607-6.

12. Quinn JJ, Chang HY. Unique features of long non-coding RNA biogenesis and function. Nat Rev Genet. 2016;17:47-62. https://doi.org/10.1038/nrg. 2015.10. 
13. Jiang W, Agrawal DK, Boosani CS. Non-coding RNAs as epigenetic gene regulators in cardiovascular diseases. Adv Exp Med Biol. 2020;1229:13348. https://doi.org/10.1007/978-981-15-1671-9_7.

14. Wang Y, Ding X, Hu H, He Y, Lu Z, Wu P, et al. Long non-coding RNA IncPCTST predicts prognosis through inhibiting progression of pancreatic cancer by downregulation of TACC-3. Int J Cancer. 2018;143:3143-54. https://doi.org/10.1002/ijc.31657.

15. Zhou B, Qi F, Wu F, Nie H, Song Y, Shao L, et al. Endogenous retrovirusderived long noncoding RNA enhances innate immune responses via derepressing RELA expression. MBio. 2019. https://doi.org/10.1128/mBio. 00937-19.

16. Wu G, Cai J, Han Y, Chen J, Huang ZP, Chen C, et al. LincRNA-p21 regulates neointima formation, vascular smooth muscle cell proliferation, apoptosis, and atherosclerosis by enhancing p53 activity. Circulation. 2014;130:1452-65. https://doi.org/10.1161/CIRCULATIONAHA.114. 011675.

17. Yang Y, Cai Y, Wu G, Chen X, Liu Y, Wang X, et al. Plasma long non-coding RNA, CoroMarker, a novel biomarker for diagnosis of coronary artery disease. Clin Sci. 2015;129:675-85. https://doi.org/10.1042/CS20150121.

18. Gao W, Zhu M, Wang H, Zhao S, Zhao D, Yang Y, et al. Association of polymorphisms in long non-coding RNA H19 with coronary artery disease risk in a Chinese population. Mutat Res. 2015;772:15-22. https://doi.org/ 10.1016/j.mrfmmm.2014.12.009.

19. Jin L, Lin X, Yang L, Fan X, Wang W, Li S, et al. AK098656, a novel vascular smooth muscle cell-dominant long noncoding RNA, promotes hypertension. Hypertension. 2018;71:262-72. https://doi.org/10.1161/HYPERTENSI ONAHA.117.09651.

20. Zhu FL, Zhang N, Ma XJ, Yang J, Sun WP, Shen YQ, et al. Circulating hematopoietic stem/progenitor cells are associated with coronary stenoses in patients with coronary heart disease. Sci Rep. 2019;9:1680. https://doi. org/10.1038/s41598-018-38298-5.

21. Semeniuk LM, Kryski AJ, Severson DL. Echocardiographic assessment of cardiac function in diabetic $\mathrm{db} / \mathrm{db}$ and transgenic $\mathrm{db} / \mathrm{db}$-hGLUT4 mice. Am J Physiol Heart Circ Physiol. 2002;283:H976-82. https://doi.org/10. 1152/ajpheart.00088.2002.

22. Chung AW, Hsiang YN, Matzke LA, McManus BM, van Breemen C, Okon EB. Reduced expression of vascular endothelial growth factor paralleled with the increased angiostatin expression resulting from the upregulated activities of matrix metalloproteinase-2 and -9 in human type 2 diabetic arterial vasculature. Circ Res. 2006;99:140-8. https://doi.org/10.1161/01. RES.0000232352.90786.fa.

23. Zhang MJ, Zhou Y, Chen L, Wang YQ, Wang X, Pi Y, et al. An overview of potential molecular mechanisms involved in VSMC phenotypic modulation. Histochem Cell Biol. 2016;145:119-30. https://doi.org/10.1007/ s00418-015-1386-3.

24. Owens GK, Kumar MS, Wamhoff BR. Molecular regulation of vascular smooth muscle cell differentiation in development and disease. Physiol Rev. 2004;84:767-801. https://doi.org/10.1152/physrev.00041.2003.

25. Liu R, Leslie KL, Martin KA. Epigenetic regulation of smooth muscle cell plasticity. Biochim Biophys Acta. 2015;1849:448-53. https://doi.org/10. 1016/j.bbagrm.2014.06.004.

26. Austin KM, Nguyen N, Javid G, Covic L, Kuliopulos A. Noncanonical matrix metalloprotease-1-protease-activated receptor-1 signaling triggers vascular smooth muscle cell dedifferentiation and arterial stenosis. J Biol Chem. 2013;288:23105-15. https://doi.org/10.1074/jbc.M113.467019.

27. Sabri A, Levy Bl, Poitevin P, Caputo L, Faggin E, Marotte F, et al. Differential roles of AT1 and AT2 receptor subtypes in vascular trophic and phenotypic changes in response to stimulation with angiotensin II. Arterioscler Thromb Vasc Biol. 1997;17:257-64. https://doi.org/10.1161/01.atv.17.2. 257.

28. Martin KA, Merenick BL, Ding M, Fetalvero KM, Rzucidlo EM, Kozul CD, et al. Rapamycin promotes vascular smooth muscle cell differentiation through insulin receptor substrate-1/phosphatidylinositol 3-kinase/Akt2 feedback signaling. J Biol Chem. 2007;282:36112-20. https://doi.org/10. 1074/jbc.M703914200.

29. Martin KA, Rzucidlo EM, Merenick BL, Fingar DC, Brown DJ, Wagner RJ, et al. The mTOR/p70 S6K1 pathway regulates vascular smooth muscle cell differentiation. Am J Physiol Cell Physiol. 2004;286:C507-17. https://doi. org/10.1152/ajpcell.00201.2003.
30. Zhao Y, Samal E, Srivastava D. Serum response factor regulates a musclespecific microRNA that targets Hand2 during cardiogenesis. Nature. 2005;436:214-20. https://doi.org/10.1038/nature03817.

31. Kuang SQ, Kwartler CS, Byanova KL, Pham J, Gong L, Prakash SK, et al. Rare, nonsynonymous variant in the smooth muscle-specific isoform of myosin heavy chain, MYH11, R247C, alters force generation in the aorta and phenotype of smooth muscle cells. Circ Res. 2012;110:1411-22. https://doi.org/10.1161/CIRCRESAHA.111.261743.

32. Hedin U, Thyberg J. Plasma fibronectin promotes modulation of arterial smooth-muscle cells from contractile to synthetic phenotype. Differentiation. 1987;33:239-46. https://doi.org/10.1111/j.1432-0436.1987.tb01563.x.

33. Devaux Y, Zangrando J, Schroen B, Creemers EE, Pedrazzini T, Chang CP, et al. Long noncoding RNAs in cardiac development and ageing. Nat Rev Cardiol. 2015;12:415-25. https://doi.org/10.1038/nrcardio.2015.55.

34. Zhu Y, Yang T, Duan J, Mu N, Zhang T. MALAT1/miR-15b-5p/MAPK1 mediates endothelial progenitor cells autophagy and affects coronary atherosclerotic heart disease via mTOR signaling pathway. Aging. 2019. https://doi.org/10.18632/aging.101766.

\section{Publisher's Note}

Springer Nature remains neutral with regard to jurisdictional claims in published maps and institutional affiliations.

Ready to submit your research? Choose BMC and benefit from:

- fast, convenient online submission

- thorough peer review by experienced researchers in your field

- rapid publication on acceptance

- support for research data, including large and complex data types

- gold Open Access which fosters wider collaboration and increased citations

- maximum visibility for your research: over 100M website views per year

At BMC, research is always in progress.

Learn more biomedcentral.com/submissions 